Middle East Journal of Science(MEJS)

journal homepage: http://mejs.ineseg.org/

\title{
THE PREPARATION OF A NEW PROTEIN BASED HPLC COLUMN PACKING MATERIAL AND ENANTIOMERIC RESOLUTION OF SOME PHARMACEUTICAL RELATED COMPOUNDS VIA THIS COLUMN
}

\author{
Ömer Erdoğan ${ }^{1}$, Giray Topal*2, Reşit Çakmak ${ }^{3}$ Murat Sünkürr ${ }^{3}$, Mutlu Canpolat ${ }^{3}$ \\ ${ }^{1}$ Adnan Menderes Üniversitesi, Aydın, Türkiye \\ ${ }^{2}$ Dicle Üniversitesi, Diyarbakır, Türkiye \\ ${ }^{3}$ Batman Üniversitesi, Diyarbakır, Türkiye \\ *gtopal@dicle.edu.tr
}

In this study, BSA was bounded to 3-chloropropyl functionalized silica gel via ethylenediamine and glutaric dialdehyde. The prepared CSP was packed into 150X4.6mm HPLC column according to slurry method. The enantiomeric resolution of some pharmaceutical related compounds such as rac-mandelic acid, rac-methyl mandelate, rac-epinephrine, rac-propranolol, rac- $\alpha$ phenylethylamine and rac-3-hydroxybutyric acid was employed in $1 \mathrm{~mL} / \mathrm{rpm}$, 1,5mL/rpm, $2 \mathrm{~mL} / \mathrm{rpm}, 2,5 \mathrm{~mL} / \mathrm{rpm}, 3 \mathrm{~mL} / \mathrm{rpm}$ flow rate in various $\mathrm{pHs}$ such $p H=6, p H=7, p H=80,1 M$ phosphate buffer. Chromatographic parameters such as $R$ and $\alpha$ were calculated for each resoluted compounds.

Key words: Enantiomeric separation, hplc, bovine serum albumin 


\title{
PROTEIN TEMELLI YENI BİR HPLC KOLON DOLGU MADDESININ HAZIRLANMASI VE BAZI İLAÇ İLIŞKIILİ RASEMIKK BİLEŞİKLERİN BU KOLON ÜZERİNDEN ENANTIYYOMERİK REZOLÜSYONU
}

\begin{abstract}
Bu çalışmada glutarik dialdehit metodu modifiye edilerek sığır serum albümin, etilendiamin ve glutarik dialdehit arakolu üzerinden 3-kloropropil silika jele bağlandi. Hazırlanan bu CSP 150X4,6 mm ebatlarındaki HPLC kolona bulamaç metoduyla doldurularak 9 farkl rasemik bileşiğin enantiyomerik rezolüsyonu sağlanmaya çalışıldı. Her bir rasemik bileşiğin etanol-heksan(1:1) karışımında 2mg/mL çözeltisi hazırlandı. Bu şekilde

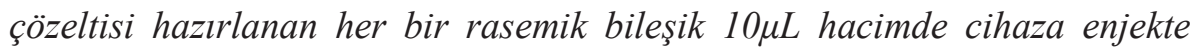
edilerek sonuçlar UV-DAD dedektörde $\lambda=270 \mathrm{~nm}$ 'de okundu. Protein temelli kiral sabit fazlarda en iyi ayırma sağlayan sodyum fosfat tamponu yürütücü faz olarak kullanildı. Farklı $p H$ 'lar $(p H=6, p H=7, p H=8)$ ve farklı akış hızlar $(1,1.5,2,2.5,3,4,5 \mathrm{~mL} / \mathrm{dk})$ denenerek enantiyomerik rezolüsyonu sağlanan rasemik bileşikler için kromatografik parametreler (RS ve $\alpha$ ) hesaplandl.
\end{abstract}

Anahtar Kelimeler: Enantiyomerik ayırma, hplc, sığır serum albumini

\section{Giriş}

Kiral ayırma, biyosistemlerde enantiyomerik ilaçların metabolik, toksikolojik ve farmakolojik olarak büyük farklılıklar göstermesinden dolayı farmasötik endüstrinin artan ilgisini üzerine çekmektedir. $\mathrm{Bu}$ yüzden enantiyomerik ayrılmayı gerçekleştirmek için birçok metot başarılı şekilde kullanılmaktadır. Günümüzde kromatografik metot en etkili yöntemlerden biridir $[1,20]$. Kiral ayırma için siklodekstrin, polisakkarit, makrosiklik antibiyotik, ligand-değişim, Pirkle, crown eter ve protein türevli birçok kiral sabit faz geliştirilmektedir. Proteinler kiral moleküllere stereoselektif olarak bağlanan, Laminoasitlerden oluşmuş, yüksek molekül ağırlıklı, doğal biyopolimerlerdir. Proteinler kompleks ve değişken konformasyona sahip oldukları için, protein temelli kiral sabit fazlar genellikle etkin enantiyomerik ayırma kapasitesine sahiptirler [52]. Bu özelliğinden dolayı enantiyomerik ayırmalar için çeşitli protein temelli kiral sabit fazlar sentezlenmektedir. Bunlar sığır ve insan serum albümini, $\alpha-1$-asit glikoprotein, avidin, sellülaz, ovoglikoprotein, tripsin, $\alpha$-kimotripsin ve pepsin [20] gibi proteinleri içermektedir.

Protein temelli kiral sabit fazları sentezlemek için birçok farklı yöntem önerilmektedir [6,53]. Proteinler içerdikleri amino, karboksil ve sülfür fonksiyonel grupları üzerinden matrikse bağlanmaktadır. Ancak reaksiyonlarda en sık amino fonksiyonel grubu kullanılmaktadır. Proteinler amino grubu üzerinden glutarik dialdehit, 1,1-karbonildiimidazol, epoksit, N,N-disüksinimidil karbonat ve triazin metotlarıyla matrikse kenetlendirilir.

1883 yılında Lord Kelvin, yunanca el anlamındaki “cheir" kelimesinden kiralite kelimesini türetmiştir. Temel parçacıklardan insanlara kadar geniş yelpazedeki nesnelerin birçoğunda kiralite gözlemlenmiştir [25]. Bu gözlem sayesinde bilim insanları, evrenin oluşumunda kiralitenin önemli bir role ve gizeme 
sahip olduğunu öne sürmüşlerdir. Evrenimizde kiralitenin varllğg ile ilgili şu örnekleri verebiliriz. Eski mısır uygarlıklarındaki mezar odalarının duvarlarında kiraliteyi tasvir eden bazı resimler çizilmiştir. Ayrıca Carnegie Galaksi Atlasında yer alan 1168 galaksiden 540'ının, durgunluk hızlarının yönü ile karşılaştırıldığında kiral olduğu bulunmuştur [33]. Birçok asimetrik yapının bulunduğu bitki ve hayvanlarda, kiralitenin etkisi belirgindir. Bitki ve hayvanlardaki sarmal yapılar onları asimetrik yapar. Kisaca, kiralite evrenimizin neredeyse her yerinde vardir.

Kiral bileşiklerin iki önemli özelliği, onları akiral bileşiklerden ayırt eder. Birincisi düzlem polarize 1şığa karşı davranışları, ikincisi ise diğer kiral bileşiklerle etkileşimleridir. Bu iki özellikten faydalanarak değişik kromatografik (HPLC, Liquid Kromatografisi ve Clay Kolon Kromatografisi) yöntemler ile kiral bileşiklerin enantiyomerlerine ayrılması literatürde bilinmektedir $[4,7,38,48,50]$. Ayrıca Kapiler Elektroforez yöntemiyle de söz konusu ayırma işlemleri yapılmaktadır.

Enantiyomerik saflığı yüksek mandelik asit gibi $\alpha$-hidroksiasitler, bir $\beta$ - blokeri olan propranolol ve kalp atışını hızlandıran, kas ve karaciğerdeki glikojeni glukoza çeviren epinefrin metabolizmadaki bu biyolojik önemlerinden dolayı ilaç sanayinde oldukça yaygın kullanım alanı bulurlar [1]. Bu nedenle kiral bileşiklerin hazırlanması ve analizi oldukça önemlidir. Kromatografik metotlarla enantiyomerik ayırma ne kadar yüksek enantiyomerik saflıkta yapılabilirse; uygulamada insan sağlı̆̆ına etkili bir tedavi gerçekleştirmek o denli başarılı olur. Çevre kimyası, ilaç sanayi ve klinik analizlerde her zaman yüksek enantiyomerik saflık istenir. Bu saflık olmazsa her açıdan istenmeyen durumlar yaşanabilir. Hatta sonu ölümle neticelenen durumlar oluşabilir [16,43]. Rasemik farmasötik bileşiklerin ayrılması için günümüzde değişik teknikler kullanılmaktadır. Bunlardan en çok uygulama alanı bulanı HPLC ve kapiler elektroforezdir $[2,8,35]$. HPLC' de proteinler silika jel üzerine farklı ara kollar yardımıyla bağlanarak bir CSP hazırlanır. Hazırlanan bu CSP çeşitli ebatlardaki HPLC kolona doldurularak, bu kolon üzerinden rasemik bileşiklerin enantiyomerik rezolüsyonu gerçekleştirilir. Bu kolonlar ticari yolla temin edilebildiği gibi araştırmacılar tarafından analitik amaçlı veya preparatif amaçlı da hazırlanabilirler [11,47].

\subsection{Kiral Sabit Fazlar}

Kiral sabit fazlar kesinlik, hız, hassaslık ve tekrar kullanılabilirlik gibi parametreler göz önüne alındığında kiralite biliminin vazgeçilmezleri arasındadır. CSP'ler akiral katı bir destek maddesi üzerine kiral bir molekülün kimyasal bağlarla bağlanması sonucu elde edilirler ve enantiyomerik rezolüsyonda çok önemli bir yere sahiptirler. Analitik, biyokimya, ilaç ve çevre endüstrisinde kromatografi ile enantiyomerlerin kiral rezolüsyon çalışmaları genellikle CSP'ler üzerinden yürütülmektedir. CSP'ler genellikle HPLC'de kullanılan çelik kolonlara doldurulmaktadır. Fakat kapiler elektroforez ve ince tabaka kromatografisi için bazı kiral kılcallar ve ince tabakalarda da kullanıldıkları bilinmektedir. Kiral kolonlar ve kapiler dolgu maddeleri; polisakkaritler, siklodekstrinler, antibiyotikler, proteinler, Pirkle tip ligand değiştiriciler ve crown eterler gibi çeşitli kiral selektörler ile paketlenmektedir [47]. 


\section{Şekil 1.1. Polisakkarit Temelli CSP'nin Yapısı}

\subsubsection{Polisakkarit Temelli Kiral Sabit Fazlar}

Selüloz, amiloz ve kitin gibi polisakkaritler, yeryüzünde bol miktarda bulunan optikçe aktif polimerlerdir. Bu polisakkaritlerin asit klorürler ve izosiyanatlarla reaksiyonu sonucu oluşan ester ya da karbamatları kiral tanıma özelliğine sahiptir. Polisakkarit temelli CSP'ler, birçok kiral bileşiğin enantiyomerik rezolüsyonunda yaygın olarak kullanılmaktadır [6,12,34,39].

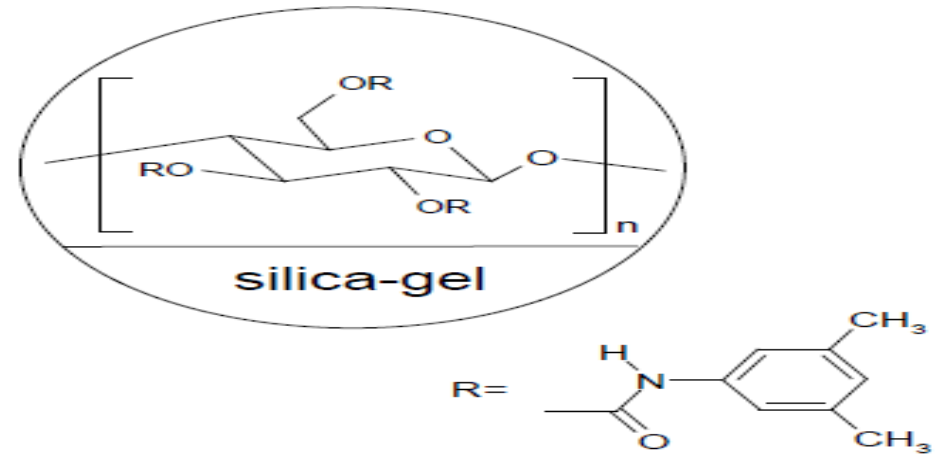

Şekil 1. Polisakkarit Temelli CSP'nin Yapısı

\subsubsection{Siklodekstrin Temelli Kiral Sabit Fazlar}

Siklodekstrinler D-(+)-glukopiranoz ünitelerinin $\alpha-(1,4)$ bağlarıyla bağlanması sonucu oluşan toroidal şekilli moleküllerdir. Siklodekstrinler "Bacillus macerans" bakterileri tarafından nişastanın sindirilmesiyle ya da siklodekstrin glikozilaz enzimi tarafından doğal olarak üretilirler. $\alpha-, \beta-$, ve $\gamma$ siklodekstrinler doğada bol miktarda bulunmaktadır ve sırasıyla altı, yedi ve sekiz glukopiranoz birimlerinin bir araya gelmesiyle oluşmaktadırlar [3, 36].

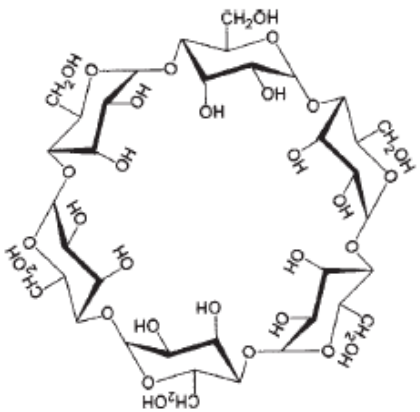

$\alpha$-siklodekstrin

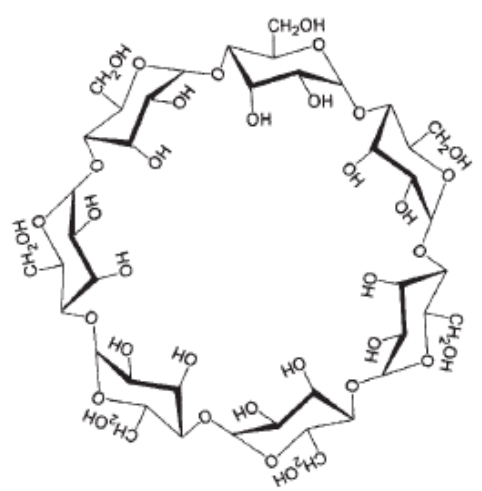

B-siklodekstrin

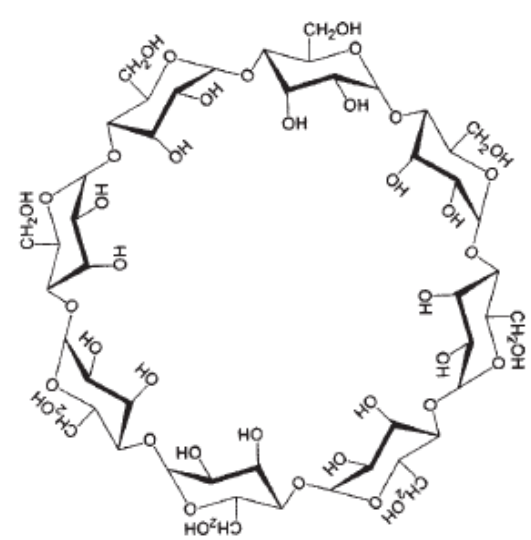

$\gamma$ - Siklodesktrin

Şekil 2. $\alpha$-, $\beta$-, ve $\gamma$ - Siklodekstrinlerin Yapısı 


\subsubsection{Makrosiklik Antibiyotik Temelli Kiral Sabit Fazlar}

Bu tür CSP'ler de vancomycin, ristocetin, teicoplanin v.b makrosiklik antibiyotikler kullanılmaktadır. İlk kullanılan antibiyotik 18 kiral merkez içeren vancomycin'dir. Vancomycin antibiyotiği, bakterinin hücre duvarındaki D-alanil-D-alanin grubuna bağlanarak bakterinin gelişimini durdurur. Bu bilgiden hareketle vancomycin ile hazırlanan CSP'de aminoasitlerin enantiyomerik rezolüsyonu denenmiş ve başarılı sonuçlar elde edilmiştir $[5,15,19]$.

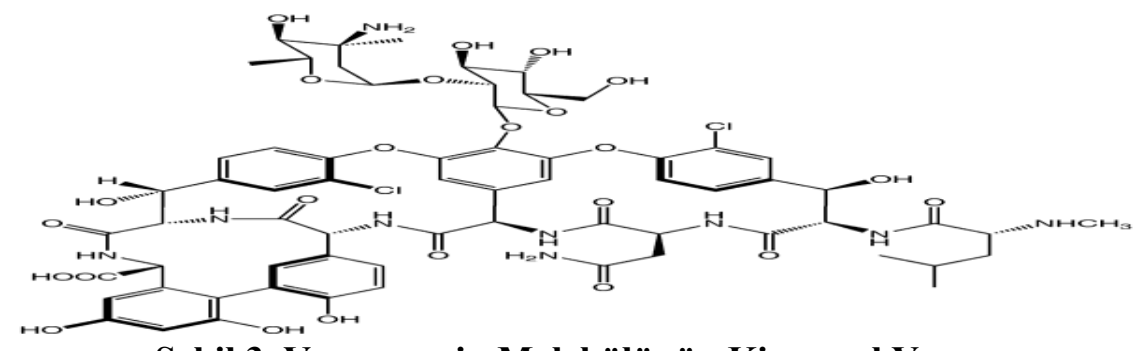

Şekil 3. Vancomycin Molekülünün Kimyasal Yapısı

\subsubsection{Pirkle Tip Kiral Sabit Fazlar}

Genellikle kiral sabit fazların tümü polimerik yapıda olan polisakkaritler ve proteinler, siklik yapıda olan siklodekstrinler ve crown eterler, kiral oyuk içeren antibiyotik temelli kiral sabit fazlar ve uygun ligand değiştiriler ile koordine edilmiş metal iyonlarını içeren ligand değişim fazları gibi bazı spesifik yapılara sahiptir. Bununla birlikte 1976'da Mikas ve çalışma grubu silikajele küçük bir kiral molekül tutturarak yeni bir CSP türüne zemin oluşturdular. Pirkle ve çalışma arkadaşları bu tip kiral sabit fazları geliştirerek, bu kolon dolgu materyallerinin Pirkle tip kiral sabit fazlar adı altında literatüre girmesini sağladılar $[9,10,30,51]$. Bu tip CSP'ler de, ya $\pi$-elektron alıcı grup ya $\pi$-elektron verici grup ya da her iki grubu birden içeren kiral bir molekül, iyonik veya kovalent bağlarla silika jele bağlanır. Bu yüzden Pirkle tip CSP'ler üç grupta sınıflandırılır( $\pi$-asidik, $\pi$-bazik, $\pi$-asidik-bazik). Kiral moleküllerdeki fenil grupları $\pi$-elektron verici eğilime sahiptir. Ancak elektronegatif atom ya da gruplar içeren fenil gruplarında $\pi$-elektron noksanlığı vardır ve bu gruplar yapıya $\pi$-elektron çekici bir özellik kazandırır $[13,38,40,41]$.

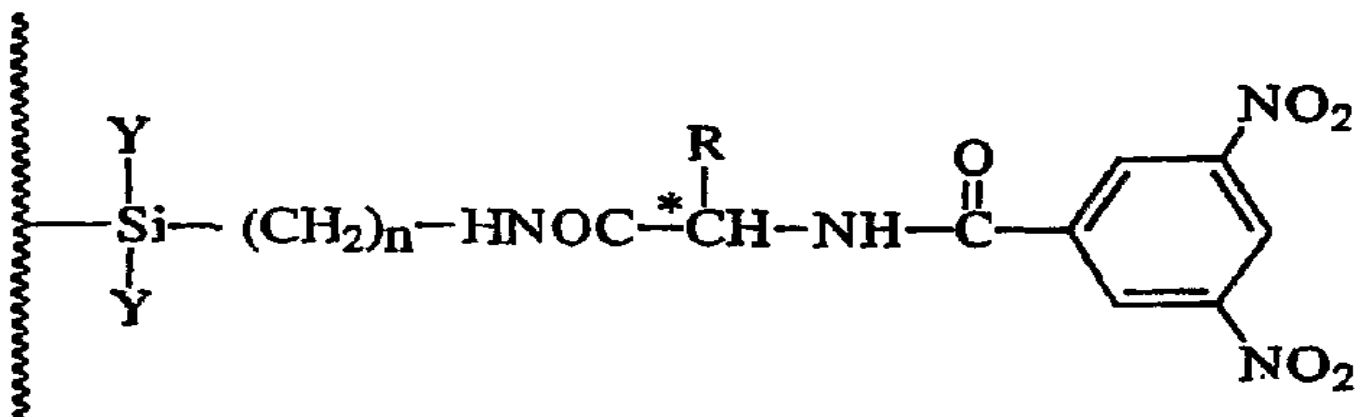

Şekil 4. Pirkle ve Arkadaşları Tarafından Hazırlanan Pirkle Tip CSP' nin Yapısı 


\subsubsection{Protein Temelli Kiral Sabit Fazlar}

Proteinler, glisin hariç kiral aminoasitlerden oluşan doğal polimerlerdir. Protein polimerler farkl1 moleküler arası bağlardan dolayı kıvrımlar içerir. Bu bağlar, protein molekülündeki kıvrımların oluklar oluşturmasını sağlar. Üç boyutlu kıvrımlı yapı proteine doğada enantiyoseçicilik kazandırır. Proteinlerle küçük moleküller arasında enantiyoseçici etkileşim en çok biyolojik sistemlerde gözlemlenir [17,18,2022].Proteinler enantiyoseçici özelliklerinden dolayı, kromatografi de CSP olarak kullanıma elverişli biyopolimerlerdir. Silika jel üzerine immobilize edilen proteinler HPLC'de birçok rasemik bileşiğin enantiyomerik rezolüsyonunda, başarılı sonuçlar vermiştir. Sıvı kromatografisinde kiral selektör olarak genelde bovine serum albumin(BSA), human serum albumin(HSA), rat serum albumin(RSA) ve guinea pig serum albumin(GPSA) proteinleri kullanılmaktadır. Bu proteinler içerisinde kiral ayırma kapasitesi en yüksek olan BSA ve HSA'dır. Bu proteinlerin yanı sıra glikoprotein temelli $\alpha$-asitglikoprotein, ovomucoid, avidin, tripsin ve enzim temelli kimotripsin, riboflavin, lizozim, pepsin, amiloglikosidaz proteinleri de kiral ayırmada kullanılmaktadır [23,24,26,32,37,46,49,52,53].

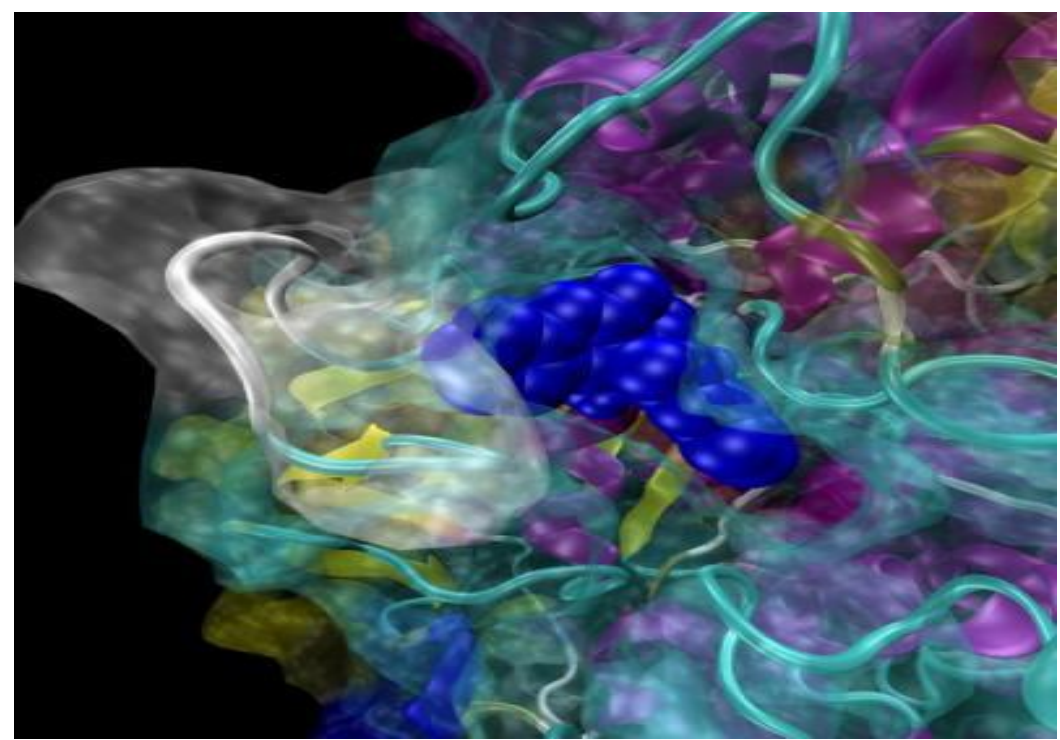

Şekil 5. Proteinin 3 Boyutlu Kiral Yapısı

\subsubsection{Kiral Crown Eter Temelli Kiral Sabit Fazlar}

Crown eterler yapılarında oksijen atomu ihtiva eden sentetik makrosiklik polieterlerdir. Oksijen atomu yerine azot ve kükürt atomu ihtiva eden Crown eterler de mevcuttur. Bu eterler sirasiyla aza Crown eterler ve tiyo Crown eterler olarak isimlendirilmektedir. Crown eterlere enantiyoseçici özellik kazandırmak için bu bileşiklere kiral bir grup bağlamak gerekir. Bu amaç için kullanılan en önemli kiral gruplar; binaftil, bifenantril, tartarik asit türevleri, aromatik bisiklo türevleri, tetrahidroindenoin v.b. dir $[14,27-29,31,42,44,45]$. 


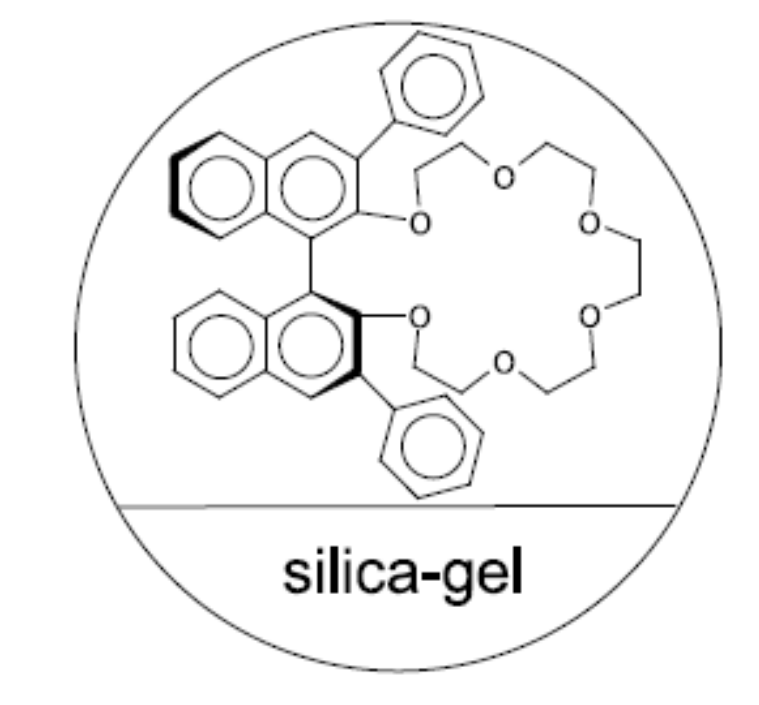

Şekil 1.6. Crown Eter Temelli CSP'nin Yapısı

\section{Yöntem}

\subsection{Materyaller}

DL-Mandelik asit, DL metil mandelat, rac-epinefrin, rac-propranolol, rac-ibuprofen, rac-naproksen, ractreonin, rac-3-hidroksibütirik asit ve rac- $\alpha$-feniletilamin gibi rasemik bileşikler; hidroklorik asit, sülfürik asit, sodyum hidroksit, sodyumhidrojenfosfat, sodyumdihidrojen fosfat, sodyum bikarbonat, sodyum sülfat gibi inorganik asit, baz ve tuzlar; sentez aşamasında kullanılan glutarik dialdehit, etilen diamin, 3-kloropropilsilikajel sigma-aldrich firmasından satın alındı. Ayrıca sentezlerde kullanılan etanol, benzen, toluen, kloroform gibi organik solventler ve HPLC grade tüm organik solventler ve bovine serum albumin MERCK firmasindan temin edildi. Deiyonize su sartorius arium comfort saf su cihazı ile elde edildi.

\subsection{BSA Temelli Kiral Sabit Fazın Hazırlanması}

Bu CSP'nin hazırlanması 3 aşamadan oluşmaktadır. İlk aşamada, 8 g CPSG alınarak $100 \mathrm{~mL}$ toluende süspansiyon haline getirildi. Bu karışıma $12 \mathrm{~g}(13,35 \mathrm{~mL})$ etilen diamin ilave edilerek karışım 4 gün boyunca reflux edildi. Çözücü ve etilen diaminin fazlası evapore edildikten sonra elde edilen katı \% 5 'lik $\mathrm{NaOH}$ çözeltisi ile yıkandı.

İkinci aşamada etilendiamin bağlanan silika jel glutaraldehit ile etkileştirildi. $\mathrm{Bu}$ işlem için, glutaraldehit'in 0,1 M fosfat tamponundaki \% 5'lik çözeltisinden $60 \mathrm{~mL}$ alınarak $9 \mathrm{~g}$ etilendiamin bağlanan silika jel ile 1 saat boyunca 25 oC' de vakum altında karıştırıldı. Karışım vakum altında süzüldü. Elde edilen katı 0 oC' deki su ile birkaç kez yıkandı.

Üçüncü aşamada, glutaraldehit bağlanan silika jelde bulunan serbest aldehit grupları ile bovin serum albumin proteinindeki aminoasitlerin serbest amino grupları arasında Schiff bazı reaksiyonu gerçekleştirildi. $\mathrm{Bu}$ işlem için, $0,8 \mathrm{~g}$ bovin serum albuminin $85 \mathrm{~mL} 100 \mathrm{mM} \mathrm{Ph}=7$ fosfat tamponundaki çözeltisi ile $9 \mathrm{~g}$ glutaraldehit bağlanmış silika jel 1 gün boyunca $5 \mathrm{oC}$ ' de karıştırıldı. Karışım vakum 
altında süzüldü. Elde edilen katı sırasıyla $1 \mathrm{M} \mathrm{NaCl}$ ve ardından soğuk su ile yıkanarak CSP kolona doldurmaya elverişli hale getirildi.

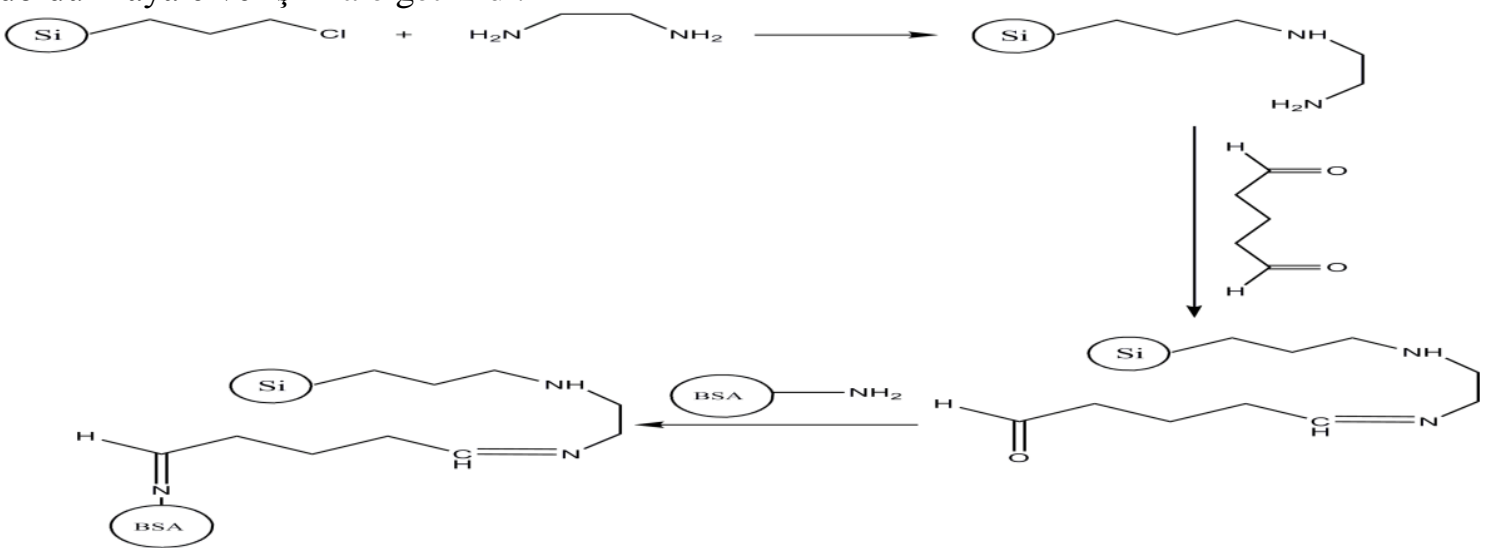

Şekil 7. BSA Temelli CSP'nin Yapısı

\subsection{HPLC Kolonun Paketlenmesi}

Bovine serum albuminin, etilen diamin ve glutaraldehit ara kolu üzerinden silika jel üzerine bağlanmasiyla hazırlanan CSP $10 \mathrm{~mL} 100 \mathrm{mM} \mathrm{pH=7}$ fosfat tamponunda süspansiyon haline getirildi. Mikropipet ile bu süspansiyon 150X4.6 cm ebatlarındaki HPLC kolona dolduruldu. CSP ile paketlenen kolon, yürütücü faz olarak 2 saat boyunca $100 \mathrm{mM} \mathrm{pH=7'lik} \mathrm{fosfat} \mathrm{tamponu} \mathrm{ile} 0.8 \mathrm{~mL} / \mathrm{dk}$ akış hızında şartlandırıldı.

\subsection{Enantiyomerik Rezolüsyon Çalışmaları}

Çizelge 1'de verilen rasemik bileşiklerin heksan-etanol(1:1) karışımında $2 \mathrm{mg} / \mathrm{mL}$ çözeltileri hazırlanarak viallere dolduruldu. Enantiyomerik rezolüsyon çalışmalarında yürütücü faz olarak $\mathrm{pH}=6$, $\mathrm{pH}=7$ ve $\mathrm{pH}=8100 \mathrm{mM}$ fosfat tamponu kullanıldı. $0.5,1.1 .5,2,2.5,3,4$ ve $5 \mathrm{~mL} / \mathrm{dk}$ akış hızlarında çalışıldı. Kolon sıcaklığı 25oC' de tutuldu. Elüentler 270nm' de UV-DAD dedektörde okundu.

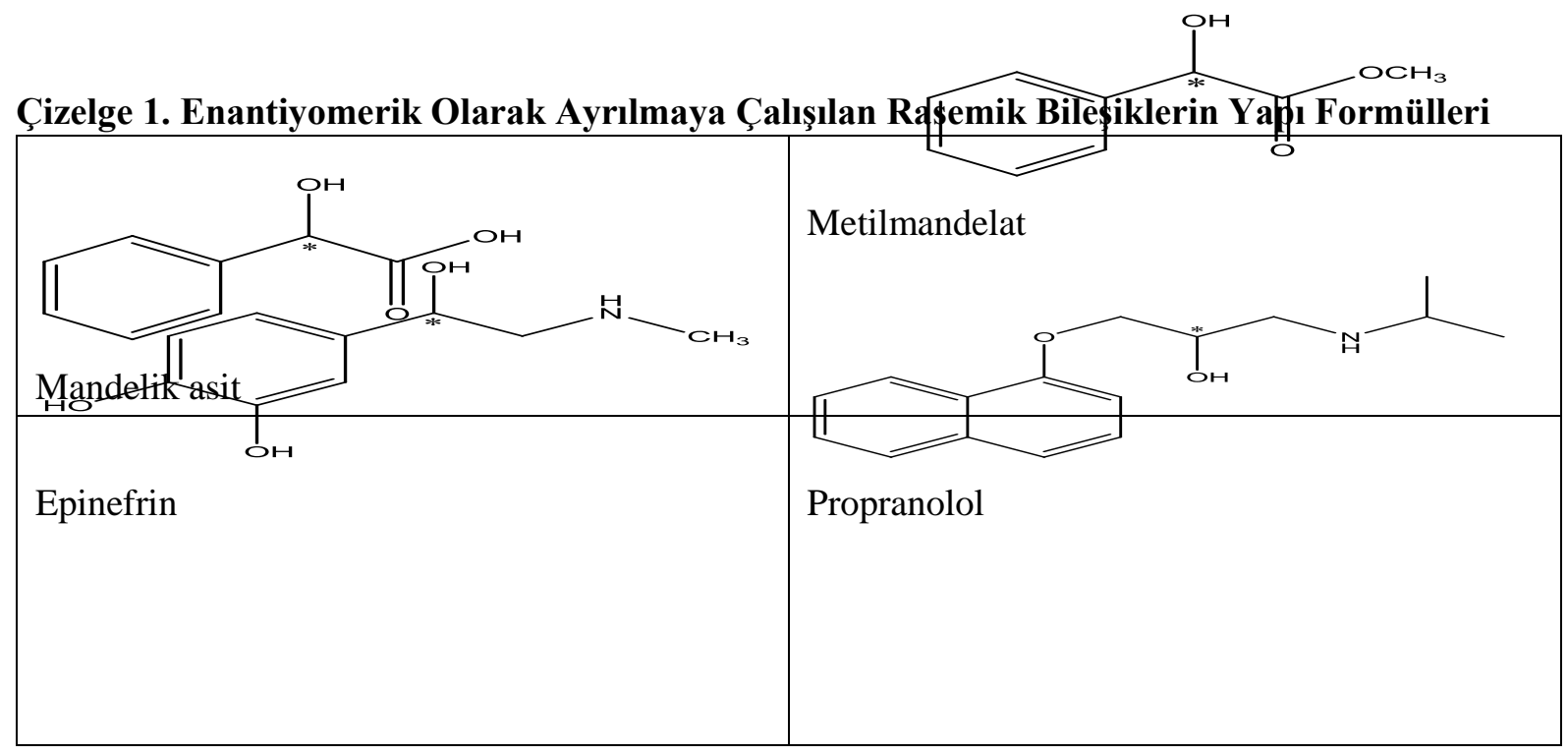




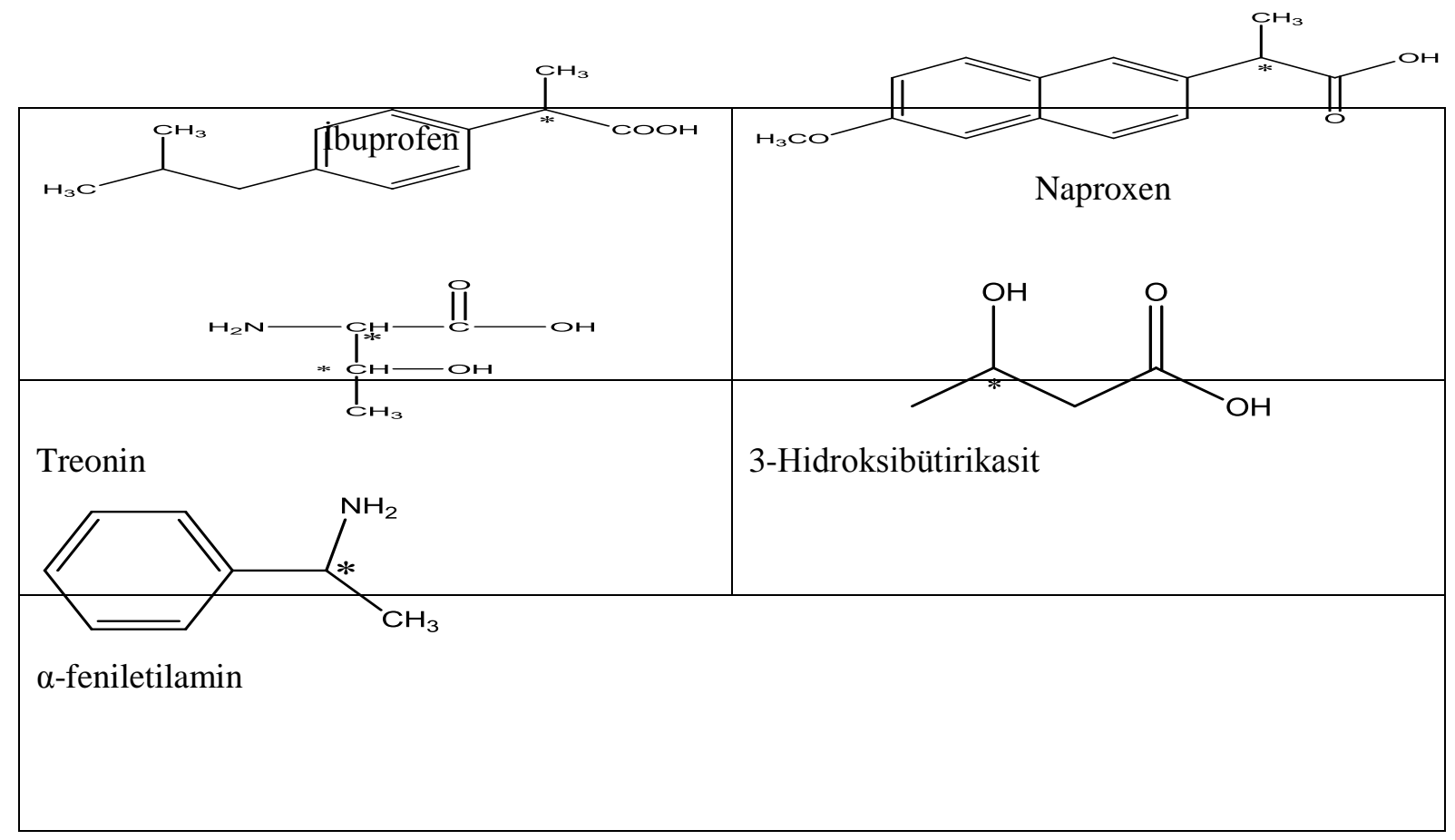

\section{Bulgular}

Bu çalışmada 9 farklı ilaç ilişkili rasemik bileşiğin enantiyomerik rezolüsyonu sağlanmaya çalışıldı. Bu bileşikler içerisinden mandelik asit, metil mandelat ve $\alpha$-feniletilamin'in enantiyomerik rezolüsyonu sağlandı. Yeni arakol üzerinden sentezlediğimiz BSA temelli CSP'nin $\mathrm{pH}=8$ 'de daha fazla sayıda rasemik bileşiği enantiyomerlerine ayırabildiği elde edilen kromatogramlara bakılarak tespit edildi. Asidik ve bazik bileşiklere nazaran metil mandelat gibi nötral bileşiklerin enantiyomerik rezolüsyonunun $\mathrm{pH}$ değişikliklerinden etkilenmediği ve bazik yapıdaki $\alpha$-feniletilamin'in bazik pH'da $(\mathrm{pH}=8)$, asidik yapıdaki mandelik asidin nötral $(\mathrm{pH}=7)$ ve bazik $(\mathrm{pH}=8) \mathrm{pH}$ larda enantiyomerlerine ayrıldığı gözlemlendi.

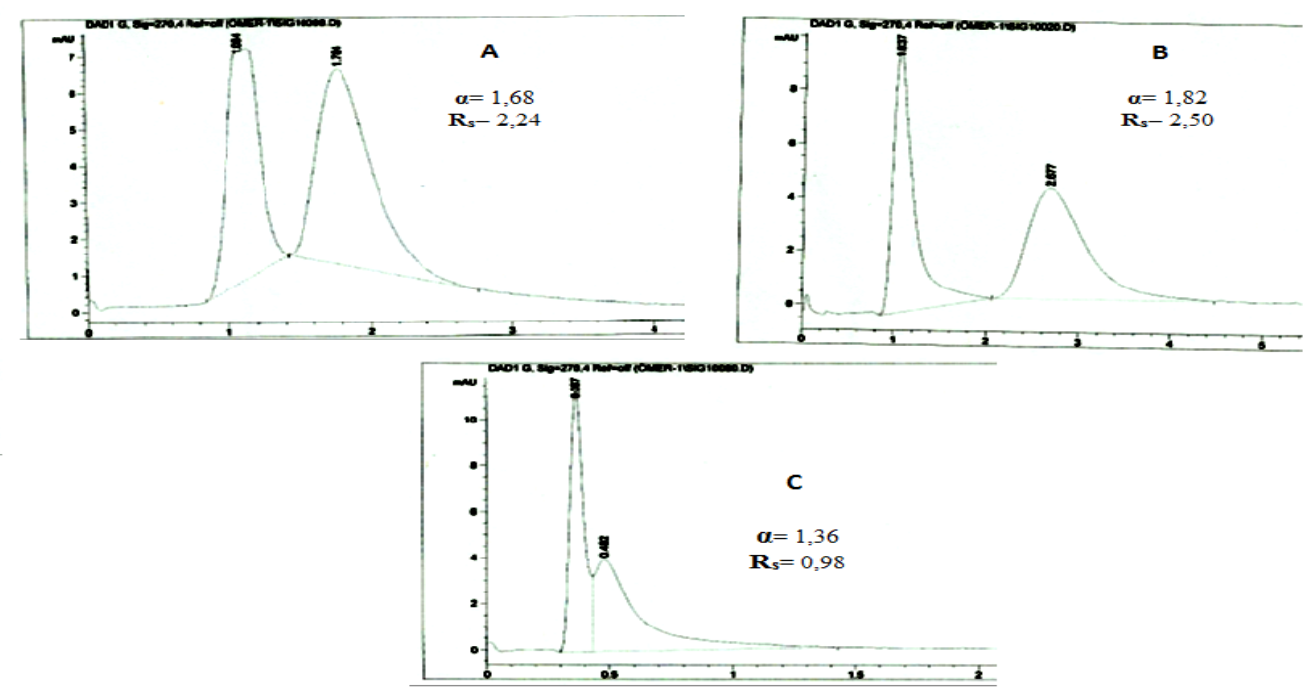

Şekil 8. A. pH=6 $1.5 \mathrm{~mL} / \mathrm{dk}$ Akış Hızında Rasemik Metil Mandelata Ait HPLC Kromatogramı B. pH=7 $1.5 \mathrm{~mL} / \mathrm{dk}$ Akış Hızında Rasemik Mandelik Asite Ait HPLC Kromatogramı C. pH=8 4 mL/dk Akış Hızında Rasemik $\alpha$-Feniletilamin'e Ait HPLC Kromatogramı 


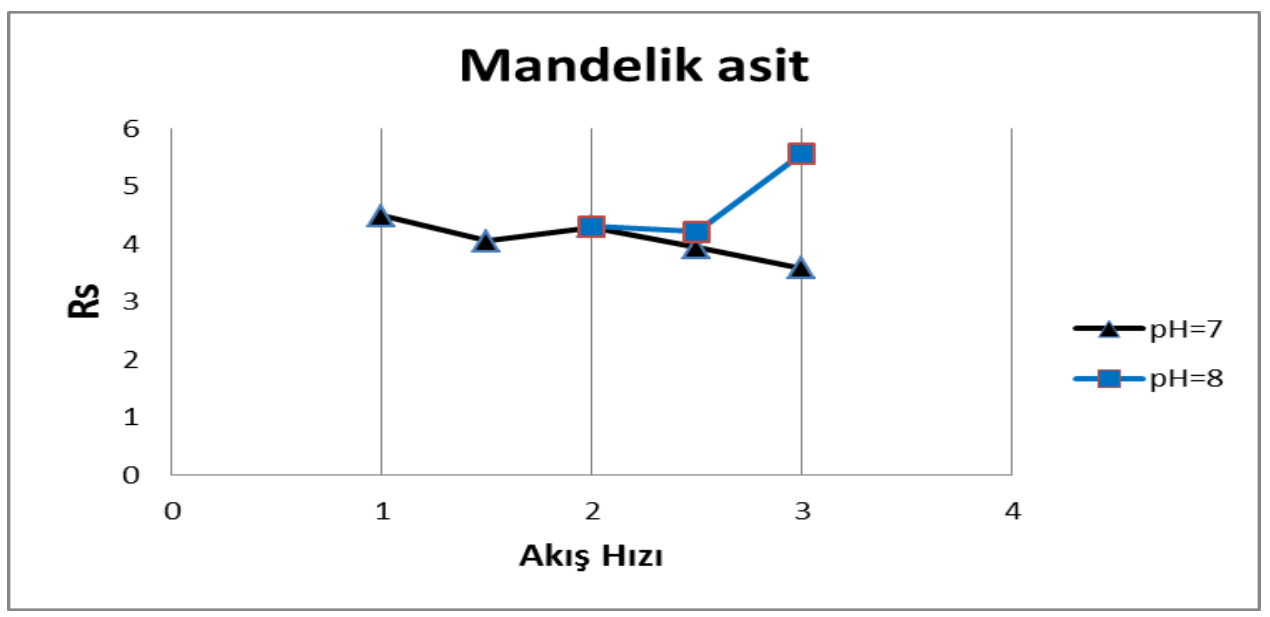

Şekil 9. Mandelik Asite Ait Akış Zamanı-Rezolüsyon Sabiti (Rs) Grafiği

Metil mandelat için en ideal ayrım $\mathrm{pH}=7$ 'de ve $1 \mathrm{~mL} / \mathrm{dk}$ akış hızında sağlandı(Rs=2,88).

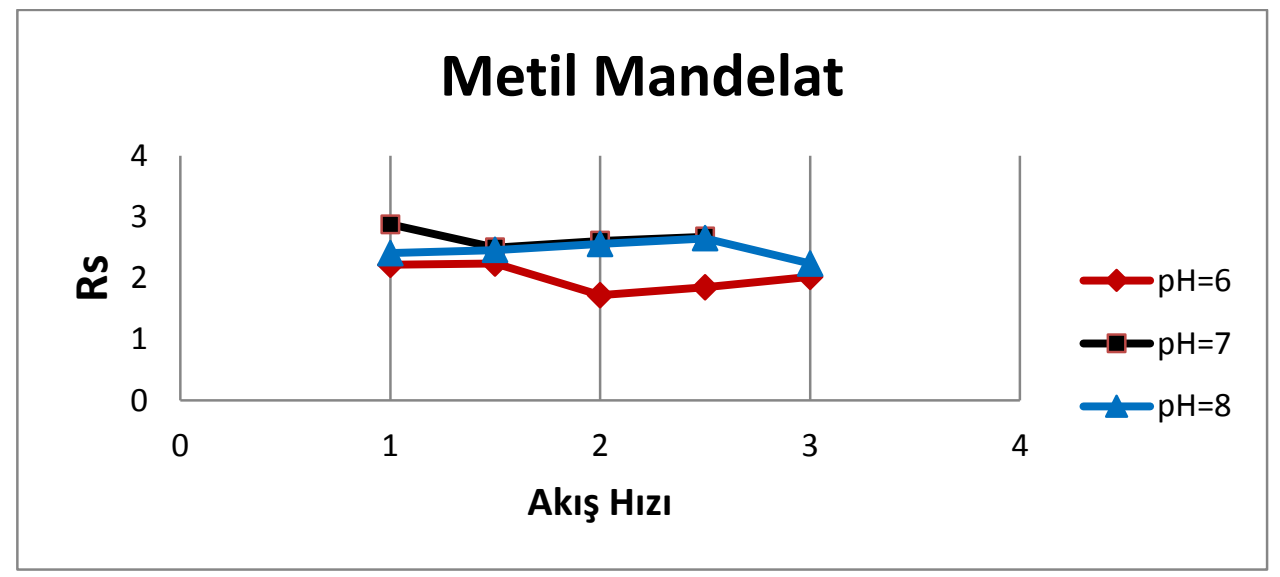

Şekil 10. Metil Mandelata Ait Akış Zamanı-Rezolüsyon Sabiti (Rs) Grafiği

Metil mandelat için en ideal ayrım $\mathrm{pH}=7$ 'de ve $1 \mathrm{~mL} / \mathrm{dk}$ akış hızında sağlandı( $\mathrm{Rs}=2,88)$.

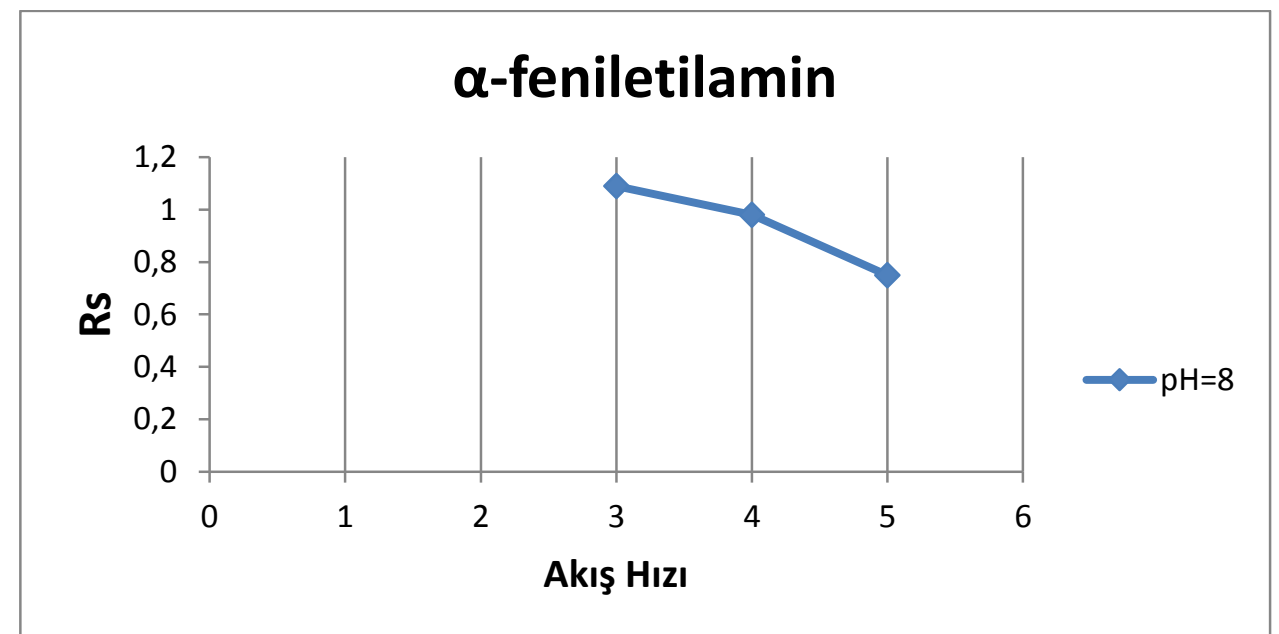

Şekil 11. Metil Mandelata Ait Akış Zamanı-Rezolüsyon Sabiti (Rs) Grafiği

$\alpha$-feniletilamin için en ideal ayrım $\mathrm{pH}=8$ 'de ve $3 \mathrm{~mL} / \mathrm{dk}$ akış hızında sağlandı(Rs=1,09). 


\section{Sonuçlar}

Enantiyomerik rezolüsyonu sağlanan farmasötik bileşiklerin yapı formüllerine bakıldığında (Şekil 4.1.) genellikle bu bileşiklerin fenil ve naftil gibi aromatik grupları ihtiva ettiği görülmektedir. Bu bilgiden hareketle sentezlediğimiz CSP ile analitler arasında kiral ayırmayı sağlayan en önemli kuvvetin $\pi-\pi$ etkileşimleri olduğunu düşünmekteyiz. Yine CSP'miz özellikle fenil ya da naftil gruplarına komşu karbonda hidroksil grubu ihtiva eden farmasötik bileşiklere karşı enantiyoseçici davranmaktadır.

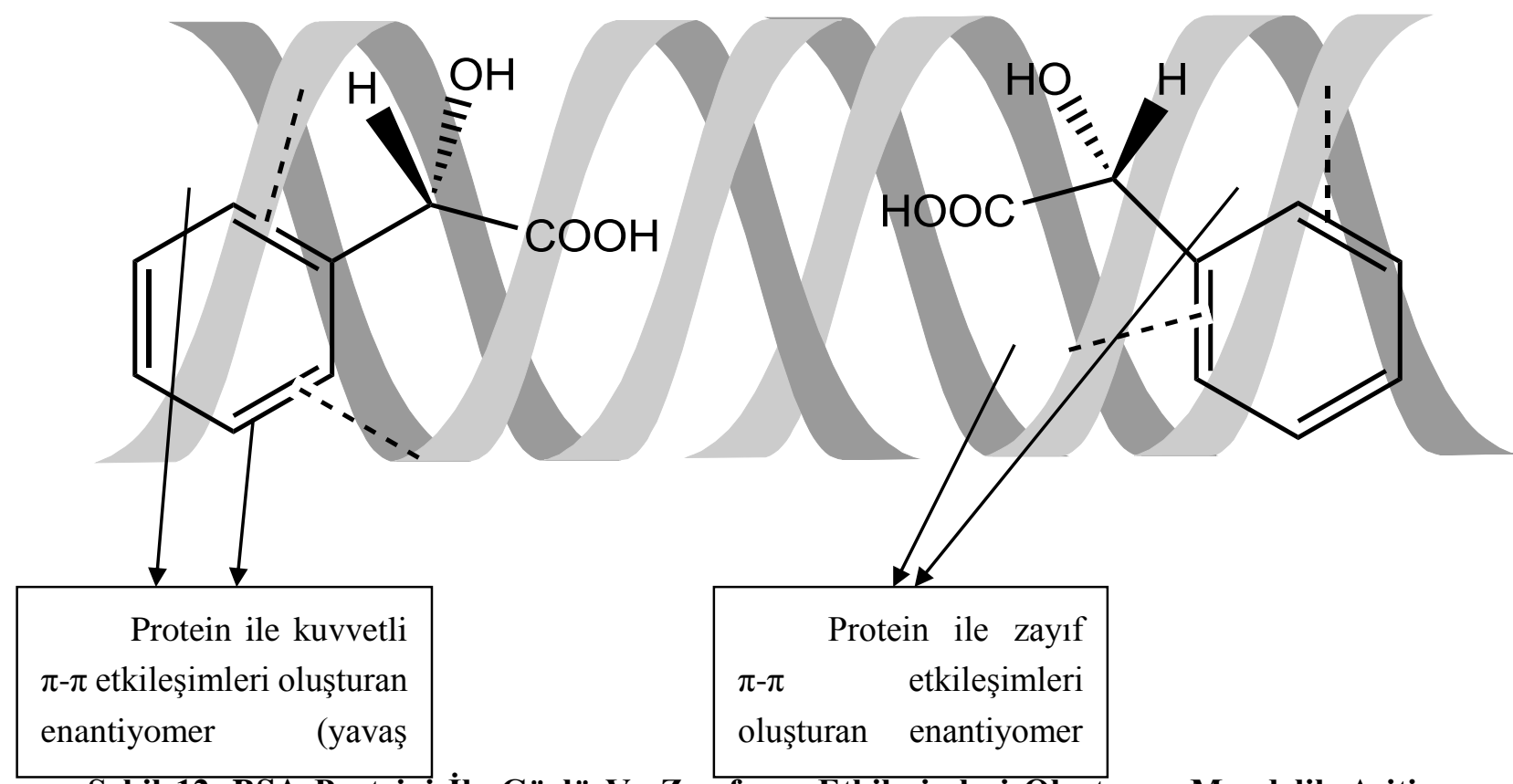

Şekil 12. BSA Proteini İle Güçlü Ve Zayıf $\pi-\pi$ Etkileşimleri Oluşturan Mandelik Asitin Enantiyomerlerin Şekilsel Gösterimi

Literatürde yer alan protein temelli CSP'lerin enantiyomerik olarak ayırmış olduğu kiral bileşiklerin kromatogramlarına bakıldığında; en kısa sürede rezolüsyon fenoprofen için 4. ve 7. dakikalar arasında yine triazin arakolu üzerinden sentezlenmiş BSA temelli CSP ile sağlanmıştır [52]. Hazırlamış olduğumuz CSP'de en kısa alıkonma süreleri mandelik asit için 0,497. ve 1,708. dakikalar arasında $(\mathrm{pH}=8,3 \mathrm{~mL} / \mathrm{dk}$ akış hızında), metil mandelat için 0,496 . ve 0,890. dakikalar arasında( $\mathrm{pH}=8$, $3 \mathrm{~mL} / \mathrm{dk}$ akış hızında) ve $\alpha$-feniletilamin için 0,295 . ve 0,367 . dakikalar arasında $(\mathrm{pH}=8,3 \mathrm{~mL} / \mathrm{dk}$ akış hızında) elde edilmiştir. Hazırladığımız CSP'nin diğer protein temelli CSP'lerden üstün tarafı, özellikle fenil ve naftil halkasına komşu karbonda hidroksil grubu içeren rasemik farmasötik bileşiklerin enantiyomerik rezolüsyonunu kısa sürede gerçekleştirmesidir.

Sonuç olarak tarafımızdan hazırlanan CSP hem ayırma gücü açısından hemde alıkonma zamanı yönünden literatürdeki analoglarıyla uyum içindedir hatta onlardan üstün yanları da vardır. Ayrıca hem kolay temin edilebilen ve hemde ticari yolla ucuz olarak satın alınabilen ekonomik üstünlüğe haizdir. Bundan başka yürütücü faz olarak fosfat tamponu kullanılması sulu fazın, yine bol bulunabilen, ekonomik ve çevre dostu özelliklerini ön plana taşımakta ve diğer mobil fazlara üstünlük sağlamaktadır. Organik solvent israfı önlenmiş olmakta ve bu durum hazırlanan CSP ve kullanılan yürütücü fazı tercih edilebilir kılmaktadır.

Kolon sıcaklığı, parçacık boyutu gibi parametreler değiştirilerek iyi bir baseline ayrımı vermeyen ve tek bir pik veren rasemik bileşiklerin de enantiyomerik rezolüsyonu sağlanabilir. Ayrıca tasarlamış 
olduğumuz etilendiamin ve glutaraldehit arakolu üzerinden asidik protein olan BSA'nın yanı sıra avidin ve kimotripsin gibi enantiyomerik ayırma gücü olan bazik proteinler silika üzerine bağlanarak yine geniş yelpazedeki rasemik farmasötik bileşiklerin enantiyomerik rezolüsyon çalışmaları yapılabilir.

\section{Kaynakça}

[1] Aboul-Enein, H. Y., \& Ali, I. (2003). Chiral separations by liquid chromatography and related technologies (Vol. 90): CRC Press.

[2] Altria, K. D. (1996). Capillary electrophoresis guidebook: principles, operation, and applications (Vol. 52): Springer.

[3] Armstrong, D. W., Chang, C.-d., \& Haing Lee, S. (1991). (R)-and (S)-Naphthylethylcarbamatesubstituted $\beta$-cyclo-dextrin bonded stationary phases for the reversed-phase liquid chromatographic separation of enantiomers. Journal of Chromatography A, 539, 83-90.

[4] Bencini, A., Benelli, C., \& Gatteschi, D. (1984). The angular overlap model for the description of the paramagnetic properties of transition metal complexes. Coordination chemistry reviews, 60 , 131-169.

[5] Berthod, A., Chen, X., Kullman, J. P., Armstrong, D. W., Gasparrini, F., D'Acquaric, I., Villani, C., \& Carotti, A. (2000). Role of the carbohydrate moieties in chiral recognition on teicoplaninbased LC stationary phases. Analytical chemistry, 72, 1767-1780.

[6] Bezhan Chankvetadze. (2012). Recent developments on polysaccharide-based chiral stationary phases for liquid-phase separation of enantiomers. Journal of Chromatography A, 1269, 26-51

[7] Bojarski, J., Aboul-Enein, H. Y., \& Ghanem, A. (2005). What's new in chromatographic enantioseparations. Current Analytical Chemistry, 1, 59-77.

[8] Cabrera, K. (2004). Applications of silica-based monolithic HPLC columns. Journal of separation science, $27,843-852$.

[9] Cakmak, R. (2008). PirkLe -tip kiral kolon kromotografisi yöntemiyle biyolojik öneme sahip kiral aminlerden ( \pm )- $\beta$-metilfeniletilamin'in rezolüsyonu. Yüksek Lisans Tezi, Harran Üniversitesi.

[10] Caude, M., Tambuté, A., \& Siret, L. (1991). Chiral stationary phases derived from tyrosine. Journal of Chromatography A, 550, 357-382.

[11] Cavazzini, A., Pasti, L., Massi, A., Marchetti, N., \& Dondi, F. (2011). Recent applications in chiral high performance liquid chromatography: A review. Analytica Chimica Acta, 706, 205-222.

[12] Chankvetadze, B., Chankvetadze, L., Sidamonidze, S., Kasashima, E., Yashima, E., \& Okamoto, Y. (1997). 3-Fluoro-, 3-chloro- and 3-bromo-5-methylphenylcarbamates of cellulose and amylose as chiral stationary phases for high-performance liquid chromatographic enantioseparation. Journal of Chromatography A, 787, 67-77.

[13] Chen, Z., Fuyumuro, T., Watabe, K., \& Hobo, T. (2004). Influence of spacers and organic modifiers on chromatographic behaviors on chiral diamide stationary phase with $\mathrm{N}-(3,5-$ dimethylbenzoyl)-D-phenylglycine. Analytica chimica acta, 518, 181-189. 
[14] Choi, H. J., Ha, H. J., Han, S. C., \& Hyun, M. H. (2008). Liquid chromatographic resolution of $\beta$-amino acids on CSPs based on optically active (3,3'-diphenyl-1,1'-binaphthyl)-20-crown-6. Analytica Chimica Acta, 619, 122-128.

[15] D’Acquarica, I., Gasparrini, F., Misiti, D., Zappia, G., Cimarelli, C., Palmieri, G., Carotti, A., Cellamare, S., \& Villani, C. (2000). Application of a new chiral stationary phase containing the glycopeptide antibiotic A-40,926 in the direct chromatographic resolution of $\beta$-amino acids. Tetrahedron: Asymmetry, 11, 2375-2385.

[16] Easson, L. H., \& Stedman, E. (1933). Studies on the relationship between chemical constitution and physiological action: Molecular dissymmetry and physiological activity. Biochemical Journal, 27, 1257.

[17] Eriksson, B.-M., \& Wallin, A. (1995). Evaluation of the liquid-chromatographic resolution of indenoindolic racemic compounds on three protein-based chiral stationary phases. Journal of Pharmaceutical and Biomedical Analysis, 13, 551-561.

[18] Fu, Y., Huang, T., Chen, B., Shen, J., Duan, X., Zhang, J., \& Li, W. (2013). Enantioselective resolution of chiral drugs using BSA functionalized magnetic nanoparticles. Separation and Purification Technology, 107, 11-18.

[19] Guillaume, Y.-C., Ismaili, L., Truong, T.-T., Nicod, L., Millet, J., \& Thomassin, M. (2002). Chiral discrimination of phenoxypropionic acid herbicide enantiomers on teicoplanin phase: methanol dependence and eluent $\mathrm{pH}$ consideration. Talanta, 58, 951-959.

[20] Haginaka, J. (2008). Recent progresses in protein-based chiral stationary phases for enantioseparations in liquid chromatography. Journal of Chromatography B, 875, 12-19.

[21] Haginaka, J. (2012). 8.9 Chromatographic Separations and Analysis: Protein and Glycoprotein Stationary Phases. In E. M. Carreira \& H. Yamamoto (Eds.), Comprehensive Chirality (pp. 153176). Amsterdam: Elsevier.

[22] Haginaka, J. (2014). Chiral Separations: Protein Stationary Phases. In Reference Module in Chemistry, Molecular Sciences and Chemical Engineering: Elsevier.

[23] Haginaka, J., Murashima, T., Fujima, H., \& Wada, H. (1993). Direct injection assay of drug enantiomers in serum on ovomucoid-bonded silica materials by liquid chromatography. Journal of Chromatography B: Biomedical Sciences and Applications, 620, 199-204.

[24] Harada, K., Yuan, Q., Nakayama, M., \& Sugii, A. (1996). Effects of organic modifiers on the chiral recognition by different types of silica-immobilized bovine serum albumin. Journal of Chromatography A, 740, 207-213.

[25] Hegstrom, R. A., \& Kondepudi, D. K. (1990). The handedness of the universe. Scientific American, 262, 108-115.

[26] Hermansson, J. (1985). Resolution of racemic aminoalcohols ( $\beta$-blockers), amines and acids as enantiomeric derivatives using a chiral $\alpha$-1-acid glycoprotein column. Journal of Chromatography A, 325, 379-384. 
[27] Hyun, M. H. (2003). Characterization of liquid chromatographic chiral separation on chiral crown ether stationary phases. Journal of separation science, 26, 242-250.

[28] Hyun, M. H. (2012). 8.13 Chromatographic Separations and Analysis: Chiral Crown EtherBased Chiral Stationary Phases. In E. M. Carreira \& H. Yamamoto (Eds.), Comprehensive Chirality (pp. 263-285). Amsterdam: Elsevier.

[29] Hyun, M. H. (2016). Liquid chromatographic enantioseparations on crown-ether based chiral stationary phases. Journal of Chromatography A, 1467, 19-32.

[30] Hyun, M. H., Cho, Y. J., Ryoo, J.-J., Jyung, K. K., \& Heo, G. S. (1995). Preparation and application of an (S)-naproxen chiral stationary phase. Journal of Chromatography A, 696, 173183.

[31] Hyun, M. H., Tan, G., \& Xue, J. Y. (2005). Unusual resolution of N-(3,5-dinitrobenzoyl)- $\alpha$ amino acids on a chiral stationary phase based on (+)-(18-crown-6)-2,3,11,12-tetracarboxylic acid. Journal of Chromatography A, 1097, 188-191.

[32] Kiyohara, S., Nakamura, M., Saito, K., Sugita, K., \& Sugo, T. (1999). Binding of dltryptophan to BSA adsorbed in multilayers by polymer chains grafted onto a porous hollow-fiber membrane in a permeation mode. Journal of Membrane Science, 152, 143-149.

[33] Kondepudi, D. K., \& Asakura, K. (2001). Chiral autocatalysis, spontaneous symmetry breaking, and stochastic behavior. Accounts of chemical research, 34, 946-954.

[34] Kubota, T., Yamamoto, C., \& Okamoto, Y. (2004). Reversed-phase liquid chromatographic enantioseparation by cycloalkylcarboxylates of cellulose and amylose. Chirality, 16, 309-313.

[35] Majors, R. E. (2006). Developments in HPLC column packing design. LC GC MagazineNorth America-Solutions for Separation Scientists, 29, 8-15.

[36] Mitchell, C. R., \& Armstrong, D. W. (2004). Cyclodextrin-based chiral stationary phases for liquid chromatography. In Chiral Separations (pp. 61-112): Springer.

[37] Narayanan, S. R. (1992). Immobilized proteins as chromatographic supports for chiral resolution. Journal of Pharmaceutical and Biomedical Analysis, 10, 251-262.

[38] Nimura, N., \& Kinoshita, T. (1986). o-Phthalaldehyde-N-acetyl-L-cysteine as a chiral derivatization reagent for liquid chromatographic optical resolution of amino acid ernantiomers and its application to conventional amino acid analysis. Journal of Chromatography A, 352, 169177.

[39] Ou, J., Lin, H., Tang, S., Zhang, Z., Dong, J., \& Zou, H. (2012). Hybrid monolithic columns coated with cellulose tris (3, 5-dimethylphenyl-carbamate) for enantioseparations in capillary electrochromatography and capillary liquid chromatography. Journal of Chromatography A, 1269, 372-378.

[40] Pirkle, W. H., \& Murray, P. G. (1996). Observations relevant to the differential intercalation of enantiomers between the strands of brush-type chiral stationary phases. Journal of Chromatography A, 719, 299-305. 
[41] Pirkle, W. H., Pochapsky, T. C., Mahler, G. S., \& Field, R. E. (1985). Chromatographic separation of the enantiomers of 2-carboalkoxyindolines and $\mathrm{N}$-aryl- $\alpha$-amino esters on chiral stationary phases derived from $\mathrm{N}$-(3,5-dinitrobenzoyl)- $\alpha$-amino acids. Journal of Chromatography A, 348, 89-96.

[42] Qin, W., Xu, S., Xu, G., Xie, Q., Wang, C., \& Xu, Z. (2013). Preparation of silica gel bound crown ether and its extraction performance towards zirconium and hafnium. Chemical Engineering Journal, 225, 528-534.

[43] Sheldon, R. A. (1993). Chirotechnology: industrial synthesis of optically active compounds: CRC press.

[44] Shinbo, T., Yamaguchi, T., Nishimura, K., \& Sugiura, M. (1987). Chromatographic separation of racemic amino acids by use of chiral crown ether-coated reversed-phase packings. Journal of Chromatography A, 405, 145-153.

[45] Steffeck, R. J., Zelechonok, Y., \& Gahm, K. H. (2002). Enantioselective separation of racemic secondary amines on a chiral crown ether-based liquid chromatography stationary phase. Journal of Chromatography A, 947, 301-305.

[46] Stewart, K. K., \& Doherty, R. F. (1973). Resolution of DL-tryptophan by affinity chromatography on bovine-serum albumin-agarose columns. Proceedings of the National Academy of Sciences, 70, 2850-2852.

[47] Tang, M., Zhang, J., Zhuang, S., \& Liu, W. (2012) Development of chiral stationary phases for high-performance liquid chromatographic separation. Trends İn Analytical Chemistry, 39, 180 194

[48] Van Gyseghem, E., Van Hemelryck, S., Daszykowski, M., Questier, F., Massart, D., \& Vander Heyden, Y. (2003). Determining orthogonal chromatographic systems prior to the development of methods to characterise impurities in drug substances. Journal of Chromatography A, 988, 77-93.

[49] Wainer, I. W., \& Chu, Y.-Q. (1988). Use of mobile phase modifiers to alter retention and stereoselectivity on a bovine serum albumin high-performance liquid chromatographic chiral stationary phase. Journal of Chromatography A, 455, 316-322.

[50] Yamagishi, A., Taniguchi, M., Imamura, Y., \& Sato, H. (1996). Clay column chromatography for optical resolution: selectivities of Lambda-[Ru (phen) 3] 2+ and Lambda-[Ru (bpy) 3] 2+ laponite columns towards 1, 1'-binaphthol. Applied clay science, 11, 1-10.

[51] Yilmaz, H., Topal, G., Cakmak, R., \& Hosgoren, H. (2010). Resolution of ( \pm )- $\beta$ methylphenylethylamine by a novel chiral stationary phase for Pirkle-type column chromatography. Chirality, 22, 252-257.

[52] Zhang, Q., Zou, H., Wang, H., \& Ni, J. (2000). Synthesis of a silica-bonded bovine serum albumin s-triazine chiral stationary phase for high-performance liquid chromatographic resolution of enantiomers. Journal of Chromatography A, 866, 173-181. 
[53] Zhou, L., Mao, B., \& Ge, Z. (2008). Comparative study of immobilized $\alpha 1$ acid glycoprotein and ovomucoid protein stationary phases for the enantiomeric separation of pharmaceutical compounds. Journal of pharmaceutical and biomedical analysis, 46, 898-906. 